This item was submitted to Loughborough's Research Repository by the author.

Items in Figshare are protected by copyright, with all rights reserved, unless otherwise indicated.

\title{
Educating and supporting tennis parents: grounded theory of parents' needs during childhood and early adolescence
}

PLEASE CITE THE PUBLISHED VERSION

http://dx.doi.org/10.1037/spy0000054

\section{PUBLISHER}

(C) American Psychological Association

\section{VERSION}

AM (Accepted Manuscript)

\section{PUBLISHER STATEMENT}

This work is made available according to the conditions of the Creative Commons Attribution-NonCommercialNoDerivatives 4.0 International (CC BY-NC-ND 4.0) licence. Full details of this licence are available at: https://creativecommons.org/licenses/by-nc-nd/4.0/

\section{LICENCE}

CC BY-NC-ND 4.0

\section{REPOSITORY RECORD}

Thrower, Samuel, Chris Harwood, and Christopher Spray. 2019. "Educating and Supporting Tennis Parents: Grounded Theory of Parents' Needs During Childhood and Early Adolescence”. figshare. https://hdl.handle.net/2134/19326. 


\section{Sport, Exercise, and Performance Psychology}

\section{Educating and Supporting Tennis Parents: A Grounded Theory of Parents' Needs during Childhood and Early Adolescence \\ --Manuscript Draft--}

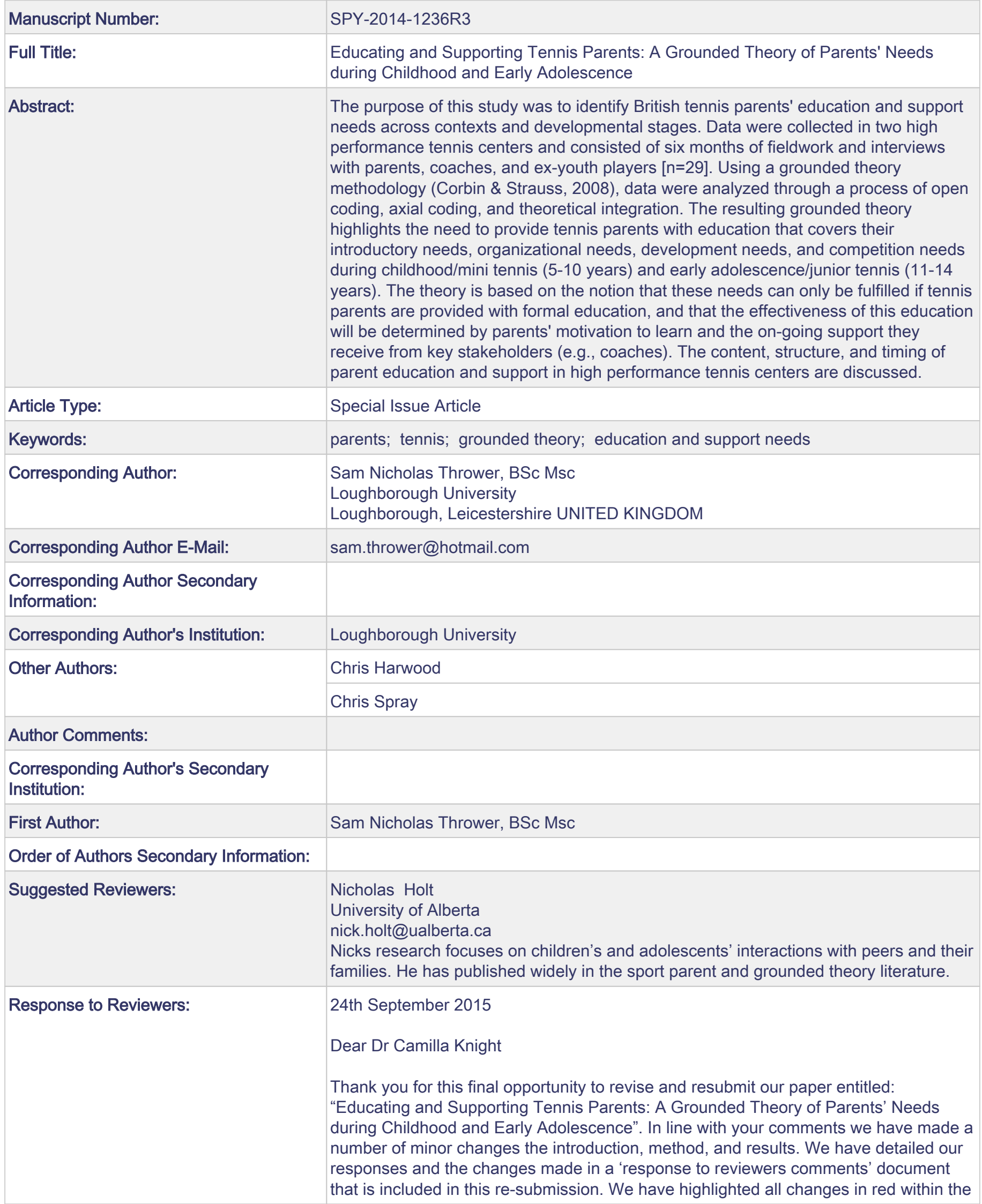


manuscript. Should you have any remaining comments, concerns, or suggestions please do not hesitate to contact us.

Yours Sincerely

Sam Thrower

School of Sport, Exercise \& Health Sciences

Loughborough University

Loughborough

LE11 3TU.

United Kingdom

Tel: 07716065298

E-mail: s.thrower@lboro.ac.uk 
Dear Dr Camilla Knight

Thank you for this final opportunity to revise and resubmit our paper entitled "Educating and Supporting Tennis Parents: A Grounded Theory of Parents' Needs during Childhood and Early Adolescence". In line with your comments we have made a number of minor changes the introduction, method, and results. We have detailed our responses and the changes made in a 'response to reviewers comments' document that is included in this resubmission. We have highlighted all changes in red within the manuscript. Should you have any remaining comments, concerns, or suggestions please do not hesitate to contact us.

Yours Sincerely

Sam Thrower

School of Sport, Exercise \& Health Sciences

Loughborough University

Loughborough

LE11 3TU.

United Kingdom

Tel: 07716065298

E-mail: s.thrower@lboro.ac.uk 


\section{7} 19 20 21
Sam N. Thrower, Chris G. Harwood, and Chris M. Spray Loughborough University

Educating and Supporting Tennis Parents: A Grounded Theory of Parents' Needs during Childhood and Early Adolescence

\section{4}

(1)
8 22

Sport, Exercise \& Health Sciences, Loughborough University, Loughborough, LE11 3TU. United

8 Kingdom. E-mail: s.thrower@lboro.ac.uk 9 


\section{Abstract}

The purpose of this study was to identify British tennis parents' education and support needs across contexts and developmental stages. Data were collected in two high performance tennis centers and consisted of six months of fieldwork and interviews with parents, coaches, and ex-youth players [n=29]. Using a grounded theory methodology (Corbin \& Strauss, 2008), data were analyzed through a process of open coding, axial coding, and theoretical integration. The resulting grounded theory highlights the need to provide tennis parents with education that covers their introductory needs, organizational needs, development needs, and competition needs during childhood/mini tennis (5-10 years) and early adolescence/junior tennis (11-14 years). The theory is based on the notion that these needs can only be fulfilled if tennis parents are provided with formal education, and that the effectiveness of this education will be determined by parents' motivation to learn and the on-going support they receive from key stakeholders (e.g., coaches). The content, structure, and timing of parent education and support in high performance tennis centers are discussed.

Key Words: parents, tennis, grounded theory, education and support needs 
Educating and Supporting Tennis Parents: A Grounded Theory of Parents' Needs during Childhood and Early Adolescence

Within the context of youth sport, there has been increasing academic interest in the development of young athletes and those responsible for their participation and progress. Parents are widely considered to have the most influence during a child's early psychosocial development throughout their initiation into sport (6-13 years) (Bloom, 1985; Côté, 1999; Wylleman \& Lavallee, 2004). Although parents are seen as essential for athletic development, they are at the same time potentially a major detriment for some young athletes (Gould, Lauer, Rolo, Jannes, \& Pennisi, 2006). Taking this into consideration, it is perhaps not surprising that within the last decade there has been growing academic interest in parents' involvement in youth sport settings (see Holt \& Knight, 2014 for a comprehensive review). This academic interest has provided an understanding of coaches' and players' perceptions of positive and negative parenting practices (e.g., Gould et al., 2006; Gould, Lauer, Rolo, Jannes, \& Pennisi, 2008; Knight, Boden, \& Holt, 2010; Knight, Neely, \& Holt, 2011; Lauer, Gould, Roman, \& Pierce, 2010a, 2010b), the stressors, emotions, and experiences associated with parenting in youth sport (e.g., Clarke \& Harwood, 2014; Dorsch, Smith \& McDonough , 2009; Harwood \& Knight, 2009a, 2009b; Omli \& LaVoi, 2012; Wiersma \& Fifer, 2008) and the positive and negative styles and behaviors parents display (e.g., Holt, Tamminen, Black, Mandigo \& Fox, 2009; Knight \& Holt, 2014).

This body of research has consistently highlighted the challenging and complex nature of parenting in youth sport and the need to educate and support parents through this process. No more so is this evident than within junior tennis, a context that has received significant attention in the literature. Much of the research within junior tennis has advocated the need to educate tennis parents about appropriate and inappropriate behaviors (e.g., Gould et al., 2008; Knight et al., 2010; Knight \& Holt, 2014). Initiating this line of enquiry, Gould and colleagues (Gould et al., 2006, 2008; Lauer et al., 2010a, 2010b) conducted a series of studies examining the role of parents in the development of 
11 junior tennis players. Through interviews, focus groups, and surveys with coaches, elite players, and

2

3

5

63

7

84

9

10

$11^{5}$

12

136

14

15

parents they highlighted a range of positive and negative parenting practices that influence players' development. During the early years, participants indicated that positive parental behaviors included parental support, effective communication, keeping players motivated, developing players' talent, developing players' psychological and social skills, and keeping tennis in perspective (Harwood \& Knight, 2012). In the later years, parents also helped with decision-making, although the range of positive behaviors parents showed decreased, specifically regarding developing tennis talent and effective communication. The range of negative parental behaviors appeared to be greatest during the middle stage with evidence of over pressuring and excessive involvement, poor emotional match reactions and embarrassing behavior, too much tennis talk, a restricted social life, and parental approval tied to results (Harwood \& Knight, 2012).

Junior tennis players have also reported preferences regarding parent behavior within the context of competitions. Knight and colleagues' (2010) findings revealed that junior tennis players' preferences for their parents' behavior appeared to vary depending on the situation. Prior to competitions, children preferred parental behaviors to be related to game-based preparation. During competition, players preferred their parents not to coach, to ensure that their comments focused on players' effort and attitude, respect the etiquette of tennis by not becoming involved in matches, and match nonverbal behaviors (such as facial expressions and body position) with supportive comments. Following competitions, children indicated that they preferred parents to provide positive and realistic feedback about their performance (Knight et al., 2010). Players concluded that supportive parental behaviors were behaviors that allowed parents to display support for and belief in their children without placing pressure upon them to win (Harwood \& Knight, 2012). However, these studies did not explore the individual factors that determine why parents engage in certain behaviors. As a result, it remains unclear if simply educating parents about appropriate and inappropriate behaviors, or creating general guidelines for parental behavior during competitions, can positively 
11 influence parents' practices.

2

32

4

63 7

In an attempt to address this limitation and gain a more complete understanding of how parental involvement can be optimized, researchers have started to explore parental behaviors within the broader parenting context (i.e., the overall environment parents create) (Knight \& Holt, 2014). Knight and Holt (2014) used interviews and focus groups with 90 youth tennis players, ex-youth players, parents, and coaches to generate a grounded theory of optimal parental involvement.

Findings revealed that optimal involvement requires parents to understand and enhance their child's individual tennis journey by having shared and communicated goals, focusing on the creation of an understanding emotional climate, and engaging in individual and flexible parenting practices (Knight \& Holt, 2014). Although this study provided an understanding of how parents' behaviors, goals, and emotional climate influence each other to optimize parental involvement, Knight \& Holt (2014) acknowledged the need for future research to explore if or how parental involvement is influenced by developmental factors. It is likely that only through understanding the wide range of factors that influence parents' involvement at different stages of their child's development, that a clearer picture of parental involvement will emerge and inform the development of stage specific educational provisions for tennis parents.

Researchers have also adopted a more parent-centered approach and explored the experiences of tennis parents from their perspective. For instance, Harwood and Knight (2009a, 2009b) explored the stressors British tennis parents experience at different stages of their child's development. Data were collected through 123 open-ended surveys and 22 interviews with tennis parents. Parental stressors in both studies centered on the organizational aspects of their children's tennis (e.g., injuries, finances, time), the competition demands (e.g., watching matches, players/opponents cheating, lack of effort), and developmental concerns (e.g., players' future in tennis, transitional decisions regarding schooling). These findings illustrate how parents' experiences are influenced by the nature of the sport (e.g., tennis), organizational system (e.g., the Lawn Tennis Association) and developmental 
stage within which they were operating. More importantly, some parents reported being unable to

develop sufficient resources to deal with the stressors they experienced, particularly during the specializing (12-16 years) and investment stages (16+ years) where these stressors were most prevalent (Harwood \& Knight, 2009b). However, it was beyond the scope of these studies to identify the education and support parents specifically wanted or needed to prevent, cope with or manage these complex and challenging demands. Consequently, further research exploring parents' education and support needs within specific junior tennis settings is clearly required.

To date, only two studies have provided an initial understanding of the education and support tennis parents require. Knight and Holt (2013a) highlighted how Western Australian parents wanted education regarding tournament involvement, psychological support to help them cope at tournaments and more social opportunities to improve their tournament experiences. Similarly, Knight and Holt (2013b) identified the additional assistance American parents require to better facilitate their children's involvement in tennis. This included understanding and negotiating player progression, education on behaving and encouraging players at tournaments, evaluating and selecting coaches, identifying and accessing financial support, and managing and maintaining schooling. Although these studies revealed that parents want education and support regarding specific aspects of tennis parenting to enhance their own involvement and experiences, neither study specifically set out to identify the needs of parents. Consequently, the extent to which these findings represent the education and support needs of parents operating in other cultures, contexts and organizational systems (e.g., British tennis) remains unclear. Furthermore, these studies are limited in that they did not explore how parents' education and support needs change or evolve across different developmental stages. The purpose of this study, therefore, was to address these gaps in the literature by developing a grounded theory of British tennis parents' education and support needs across contexts and developmental stages. Based on the lack of research, or a framework, to coherently guide practice within this area, a grounded theory approach (Corbin \& Strauss, 2008) was used to 
answer the following research questions: 'What are British tennis parents' education and support

needs?', 'how are these needs influenced by the culture, organizational system and developmental stages within which parents operate?', and 'how can parents education and support needs be

fulfilled?'. Parent education within the current study is considered as "systematic activities implemented by professionals to assist parents in accomplishing specific goals or outcomes with their children" (Mahoney et al., 1999, p.131). Parent education differs from support in that the primary purpose of the former is instructing the parent rather than encouraging or providing social support to the parent (Mahoney et al., 1999).

\section{Method}

\section{Methodological Overview}

A qualitative approach was used to capture the multiple social interactions and complexities that characterize parental involvement within junior tennis (Horn \& Horn, 2007). Specifically, the current study used a 'total' grounded theory methodology (Weed, 2009). Corbin and Strauss' (2008) variant of grounded theory was considered as a particularly salient methodology for understanding tennis parents' education and support needs as it offers insight, enhanced understanding, and importantly within the context of the current study, provides a meaningful guide for action aimed at practitioners. Consistent with this variant of grounded theory, the present study was conducted from a pragmatic philosophical perspective. Pragmatism assumes that knowledge is created and is meaningful in relation to individuals' actions and interactions (Dewey, 1922).

\section{Research Setting: British High Performance Tennis Centers}

Following institutional ethical approval, purposeful sampling was used to select two high performance tennis centers (one with international status) in Great Britain that were geographically suitable and would provide access to the range of parents (i.e., parents of players across all levels and ages) needed to address the research questions. Following an initial visit, directors at both centers agreed to allow the first author access to all areas of their centers. Prior to the study commencing, 
11

2

${ }_{4}^{3} 2$

5

63

7

84

10

$11^{5}$

12

136

14

15

$16^{7}$

17

188

19

20

21

22

2310

24

2511

26

27

2812

29

3013

31

32

$33^{14}$

34

3515

36

37

$38^{16}$

39

$4 \mathfrak{\Theta 1}$

41

4218

44

4519

46

$47_{20}$

48

49 $50^{21}$ 51

522

53

54

$55^{23}$

56

5724

58

59

parents, coaches and support staff at each tennis center were emailed an information sheet. Although

the current study focused on parents, coaches, and support staff were also informed about the

research to allow for a flexible data collection plan (Holt \& Tamminen, 2010). Due to the number of individuals regularly attending each center, it was not considered practical to seek written consent from everyone entering the research setting. Therefore, parents, coaches, and support staff were informed that they had to withdraw by 'opting out' should they not wish to be observed.

\section{Participants and Sampling}

Consistent with the core elements of a grounded theory methodology (Corbin \& Strauss,

2008), purposeful sampling was used to recruit tennis parents, with players aged between five and 18 years, for informal conversations. During fieldwork, I (the first author) continuously moved between centers and tennis parents identifying important concepts through these informal conversations. It is important to note that during initial interactions, individuals were provided with a verbal explanation of the research, data collection methods, and withdrawal procedures. Following initial analysis, there were then several phases of data collection that were directed by these emerging concepts. This process of theoretical sampling (Corbin \& Strauss, 2008) began by selecting parents with children at different levels and developmental stages for informal conversations to identify general patterns and variations in parents' education and support needs. As data collection and analysis progressed, parents from each stage who were considered to be 'information rich' were recruited in person and asked to participate in a formal interview to expand and refine these emerging concepts. As the theory began to take shape, the need to sample experienced coaches and ex-players (18+ years) working in the centers were identified, as they could (due to their experience) provide a broader understanding of parents' education and support needs, the relationships between them and how they can be fulfilled. The final interview sample consisted of 29 participants, including five parents of mini tennis players (5-10 years), eight parents of junior tennis players (11-14 years), 12 coaches and four ex-youth national and international level players (see Table 1). 


\section{Data Collection}

Phase 1: Fieldwork. A prolonged period of fieldwork (6 months) was used to explore how parents' education and support needs are related to the culture, organizational system and developmental stages of British tennis. This was deemed necessary to share participants' experiences and ascertain tacit knowledge by delving beneath the surface to explore issues that are assumed, implicit, and have become part of participants' common sense (Tracey, 2010). I entered the research sites with the purpose of understanding tennis parents' education and support needs and adopted the role of an 'overt researcher' (Corbin \& Strauss, 2008). However, I did not enter with any preconceived notions about what may emerge. Theoretical sensitivity was further enhanced by being a relative outsider within high performance tennis centers, which enabled me to minimize the danger of taking in any negative or misleading preconceptions (Weed, 2009).

Initial involvement was characterized by complete immersion that involved 'living alongside' the participants in each performance setting for a period of 4 weeks, with visits to each center changing on a weekly rotation. Fieldwork subsequently involved living the 'tennis parent lifestyle' by aligning myself with the hours in which parents attended the centers for training (usually from 47pm Monday-Friday) and travelling to tournaments at weekends. During this period, data were collected by watching what happened (observation), listening to what was said and asking questions through informal conversations (Holt, Tamminen, Black, Sehn, \& Wall, 2008). Participant observations and informal conversations were conducted in various settings including offices, cafés, classrooms, meeting rooms, gyms, restaurants, and tennis courts, although the majority of data were collected on the balcony during evening training sessions. Informal conversations were used as a way for participants to express their own or others' education and support needs but also their perceptions, views, and opinions. Jotted notes (on a mobile phone) were used to capture and record key observations, verbatim quotes, and informal communications whilst immersed in the field. Following each day in the field, jotted notes were used to reconstruct precise and detailed written descriptive 
accounts of the scene, settings, and events observed each day. This six-month period of fieldwork took place from December 2012 to May 2013 and included approximately 490 hours of involvement.

Phase 2: Interview phase. Phase two involved interviews with participants to narrow the broad range of topics discussed during informal conversations and gather specific data in relation to concepts and categories. A semi-structured interview guide was developed and constantly refined during fieldwork to focus on these emerging concepts and categories (Tamminen \& Holt, 2012). In preparation for the interview, participants were asked to reflect on their current and past experiences and plot the challenges/demands they had faced as a tennis parent (or in relation to tennis parents) at each developmental stage along a timeline (Sparkes \& Smith, 2014). Interview questions were openended to allow new themes to emerge, and focused on exploring the broad challenges/demands tennis parents face at each developmental stage (e.g., 'what did you find difficult or challenging about being a tennis parent during [developmental stage]?') and the education and support tennis parents' need during each stage (e.g., 'based on your experience, what education do you think parents need during [development stage]?') (Examples taken from parent interview guide). All participants were provided with their transcript and confirmed that it represented an accurate reflection of their views.

\section{Data Analysis}

Data analysis began after the first data were collected and continued in an iterative manner to ensure interplay between data collection and analysis (Corbin \& Strauss, 2008; Tamminen \& Holt, 2012). Informal data analysis started by reading the field notes or transcripts closely to become personally immersed in the data. Formal data analysis included three levels of coding: open coding, axial coding, and theoretical integration (Corbin \& Strauss, 2008). Open coding was used to fracture the field notes and transcripts into concepts. For example, raw data extracts that related to parents' education or support needs were identified and distinguished based on their properties (i.e., characteristics that defined a need) and dimensions (i.e., the specific developmental stage when the need occurred) (Corbin \& Strauss, 2008). As analysis continued, concepts referring to similar 
11 2

education and support needs were then gathered together and reassembled to create higher-order

categories (e.g., competition needs) and subcategories (e.g., pre-match roles). To ensure that these higher-order categories 'fitted' with the incidents and phenomena they represented, constant comparative methods were used to compare and examine concepts, subcategories, and categories. As additional data were gathered, coded concepts were also compared to existing data, modified to incorporate new data and subsequently (re) categorized.

Axial coding (Corbin \& Strauss, 2008) was used to develop and describe the links and relationships between parents' education and support needs both within and across developmental stages. Specifically, a conditional/consequential matrix (see Figure 1) was used to analyze the data for context and create structural links between social (macro level), organizational, developmental (meso level) and inter-intrapersonal (micro level) conditions. These contextual conditions were then used to understand parents' actions/interactions/emotions and consequences (Corbin \& Strauss, 2008). This matrix helped locate parents' education and support needs and understand how they fitted together to create an overall educational process. The final stage of coding, theoretical integration was used to link categories around the core category (i.e., supportive learning environment), add density to poorly developed categories, and refine the theoretical framework (Corbin \& Strauss, 2008). A 'supportive learning environment' was considered to be the core category as it related to and underpinned all of parents' specific educational needs, had the greatest explanatory value, and accounted for the variation in tennis parent behavior.

A number of techniques were used to facilitate coding throughout data collection and analysis. Analytical memos and diagrams were used to clarify, elaborate, extend, and integrate relationships between concepts, subcategories, and categories. This involved questioning the data (e.g., "what is happening here?") and writing 'relational statements' about nature of the relationship between parents' education and support needs (Corbin \& Strauss, 2008). Put simply, these tools were used to think conceptually in order to develop theoretical connections and comparisons as they evolved. 
Although the first author was familiar with the sport parenting literature, a delayed literature review was conducted in order to maintain theoretical sensitivity and examine the coherence of the theory within the tennis parenting literature. Previous research was used to compare, contrast, and integrate findings and terminology from the current study and highlight connections to relevant theories and constructs (Tamminen \& Holt, 2012). Following these coding phases, all participants were provided with the grounded theory model as well as a descriptive summary of the findings and asked to comment on how well the results 'fitted' their own experiences or views. The subsequent feedback was used to refine, develop, and further 'ground' the theory in the participants' experiences (Corbin \& Strauss, 2008). Five sport psychology practitioners and seven sport psychology researchers also provided feedback on the general coherence of the model and its practicality as a guide for action when working with tennis parents.

\section{Results}

The process of data collection and analysis led to the development of a substantive grounded theory of British tennis parents' education and support needs across contexts and developmental stages (see Figure 2). This section begins by providing an overview of the stages of parent education upon which the theory is based. The core category (i.e., supportive learning environment) is then explained. Next, parents' introductory needs are described. Following this, two educational subprocesses are explained which incorporate parents' education and support needs during childhood/mini tennis and early adolescence/junior tennis respectively. It is these sections that form the basis for the theoretical claims made in the final section.

\section{Parent Education Stages}

The current grounded theory focuses on tennis parents' education and support needs during two sport specific developmental stages: childhood/mini tennis (5-10 years) and early adolescence/junior tennis (11-14 years). The parents of players in mid-to-late adolescence (15+ years) rarely attended high performance centers, and therefore, this stage was not included in the current 
grounded theory. The parent education stages were based upon two factors: 1) the stages of talent development that coaches and directors believed were important for junior British tennis players, and 2) the national governing body's (i.e., Lawn Tennis Association [LTA]) age group competition structure. For instance, from 5-10 years of age, children in Britain play mini tennis on smaller courts, using shorter rackets and lower bouncing balls, before progressing to play full size tennis from between the ages of 10 and 11 years. Therefore, we have matched these developmental considerations and competition age groups as closely as possible based upon players' chronological age to produce two key stages for British tennis parent education.

\section{Core Category: Supportive Learning Environment (a)}

During fieldwork, it became clear that the extent to which parents' education and support needs were fulfilled was dependent on both their willingness to learn and the level of education and on-going support they received in high performance centers. As one ex-player explained: "I think the biggest area would be willing to learn...willing to take things on board and admit that they [parents] don't know everything" (Ex-player 2). Despite this, financial implications and on-court commitments meant that coaches did not have time to provide education and on-going support to all tennis parents. One coach explained the current scenario:

The current scenario is that it is left to the coaches of the players and, therefore, you are leaving parent education to chance. You get some coaches who are very good at developing relationships with parents, who are very keen to work with parents, and are happy to pick up the phone at $8 \mathrm{pm}$ at night and discuss this and that. But on the other hand, you'll have other coaches who have less interest in that and don't want to be involved (Coach 6).

Observations revealed that although the amount of education and support that parents received was influenced by the parent-coach relationship, it was mostly dependent on the standard of their child. For instance, the only parents who received structured education and on-going support in the form of regular coach meetings were parents of full time players (i.e., players who trained and 
were educated at the center). In a small number of cases psychologists were used to provide

additional support to these parents when individual needs went beyond coaches' competencies (e.g., children with mental health problems or developmental disorders).

In contrast, the majority of tennis parents received very little education or support and were reliant upon self-education (i.e., researching information) or brief informal interactions with coaches and other parents on the courtside. As one parent explained: "Through talking to other people, you learn bits of information, and you build up your own knowledge which will always happen" (Parent 3). Although participants felt that parents would benefit from education on how to develop and maintain relationships with other parents and coaches, they recognized that relying solely on informal learning meant that parents often struggled to develop the knowledge needed to fulfill their roles. The following quote illustrates this point: "As a mum, the lack of knowledge is challenging...I find it difficult to get information, specific to the stage and level that [child's name] is at and how it all works" (Parent 2).

Therefore, the grounded theory is based on the notion that parents' education and support needs will only be fulfilled when parents are placed in a supportive learning environment that provides them with structured education, and that the effectiveness of that education is determined by their willingness to learn and the on-going support they receive from key stakeholders (e.g., coaches, psychologists, mentor parents). The following quote from an experienced coach supports these points: I think the key thing with this is that the model works when parents are educated and they are working on self-development, that model works. They [parents] also need support in terms of keeping them on track with things, because they will often come off the rails a little bit...in those meetings a lot of it is reviewing the parents' performance through self-reflection, that's where they learn and develop (Coach 3).

\section{Introductory Needs (b)}

To create a supportive learning environment, participants felt that tennis parents need to be 
educated, when they first enter high performance centers, about the social factors that will influence their overall type of involvement. Coaches felt that tennis parents' type of involvement (e.g., nonsupportive, supportive, or pressurizing) will be influenced by the financial and time demands of tennis, their own reasons for involvement, and their knowledge of the sport.

Financial and time demands. Participants believed that the financial and time demands of tennis had a significant influence on whether parents' could support their child's participation in tennis. Informal conversations revealed that for the majority of parents, the time (e.g., travelling, watching) and financial commitment (e.g., individual coaching, indoor court bookings, equipment) of tennis participation negatively impacted upon their personal, social, work, and family lives and could be a significant cause of financial strain. As a result, participants felt that parents need educating from the start "about cost and how cost can be mitigated because it doesn't get cheaper. Give them [new tennis parents] an idea of cost because you don't want to put people off but you don't want people to start and find out they can't afford it" (Parent 8).

In addition to this, coaches and players felt that providing the aforementioned financial and time commitment can cause some parents to place more pressure on their children to be successful as they "feel like they need to get a return on their investment" (Ex-player 4). The following quote from a coach captures the education that parents need in relation to this point:

The biggest challenge for parents to understand is that it's an unconditional journey you are going on where you can put all this money and time in, but there are no guarantees. So then it has to come back to 'why are we doing it?' Well, you are going to develop so many life skills for these kids, and the parents have to buy into that (Coach 3).

Reasons for involvement. Another social factor influencing parents' type of involvement was the goals they had for their child's tennis participation. Participants felt that some parents encouraged their children to play tennis "because they wish they had achieved, or they want to see their child in a certain limelight" (Parent 9). One coach explained how detrimental this type of 
11 involvement can be: "You see quite a lot of parents living what their life could have been if they've

2

3 4

not quite made it, what their life could have been through their kid, and that puts serious amounts of pressure on that player; they are playing for themselves and their parents which can be quite destructive. I've seen it quite a few times" (Coach 12). Coaches felt that parents should be educated about the multiple benefits of tennis participation (e.g., physical, psychological, social and academic) and encouraged to identify other goals for their child's participation in the sport in order to manage their expectations and keep tennis in perspective. Coaches believed this would also prevent parents placing pressure on their child if they believed they were off track, not instantly successful or went through a bad spell of form.

Knowledge of tennis. A final social factor influencing parents' type of involvement was their knowledge and understanding of tennis. Coaches felt that parents who lack an understanding of tennis were not always able to provide the support their child needed to develop and progress within tennis. That is, parents were less able to show an interest in their child's tennis performance, relate to their on-court experiences or help them understand the sport (e.g., rules, stages, demands). The following quote illustrates how difficult providing emotional support can be for parents who have not played individual sports:

Understanding what your child is going through out there is difficult particularly if parents don’t either play tennis or often not played any individual sport at all...Just put yourself in their shoes a little bit and try to understand what it's like to play tennis and what it's like to compete at tennis. If they were able to understand that they would empathize more with what it is like to play the sport (Coach 6).

Specifically, coaches and players felt that all parents must be educated about the courts, rules, scoring systems and physical, technical, tactical, and psychological demands of tennis in order to relate to what their child is going through on court and be able to provide both emotional and informational support. One mother, who played tennis, explained during an informal chat how she 
believed that all "parents should have a go at it [tennis] and feel how lonely and frustrating it is when

it's going wrong". This knowledge of the sport was also considered to be vital for parents' own appreciation, enjoyment, and long-term engagement in their child's tennis journey.

\section{An Educational Sub-Process for Tennis Parents during Childhood/Mini Tennis (c)}

Once involved, parents' educational needs were determined by their child's developmental stage. The following section represents an educational sub-process for parents during childhood/mini tennis, and consists of the following categories: childhood/mini tennis organizational needs, childhood/mini tennis development needs and competition needs (see Figure 2).

Childhood/Mini tennis organizational needs (d). When parents were regularly attending high performance centers, participants felt that they need to be educated about the LTA's mini tennis organizational system. Participants described how new tennis parents are often left on their own "trying to understand and make sense of what is quite a complicated system" (Coach 6) and because it is a "learn as you go through process not many parents get it right" (Ex-player 1). Specifically, participants felt that mini tennis parents need educating about the age-related stages (i.e., mini red, mini orange, mini green), court sizes, equipment and scoring systems. The following quote highlights the uninformed starting point for many mini tennis parents: “I know it sounds silly but it didn’t click with the color of the ball until a few months in. I thought it was more for convenience at first, I thought the orange group meant it was a fun session; it wasn't until several months later I realized it was technical" (Parent 2). During informal chats, it was clear that some parents did not understand what age groups their child could compete in, what grade of tournaments to enter, how to enter them, or what to expect when attending mini tennis tournaments. The following quote highlights the need for education to cover these topics:

One of the most important things to be covered in education is competition. Explain to parents what competition is because they don't invariably understand, and I think it takes such a long time to understand, so one of the things you could do simply is to make it 
understandable. It isn't straightforward and coaches don't necessarily help the parents, so often it's parents having to find out for themselves (Coach 6).

Additionally, parents consistently referred to a lack of understanding around the mini tennis talent identification (ID) and development system that starts during this stage. The following quote from a coach captures the education parents need: "The education is very much understand the way that the performance set up works, the systems, how talent ID works, what does it mean, what does it lead to, and what are the implications for their child...so they are well equipped because everybody comes from different starting points" (Coach 6).

Childhood/Mini tennis development needs (e). Participants recognized that the short term nature of the LTA's mini tennis organizational system (i.e., mini tennis ratings and talent ID) often causes parents to become "obsessed with results" (Coach 1) during this stage. Informal chats revealed that this short-term focus caused some parents to adopt a 'more is better' viewpoint and encourage their child to train multiple times a week (including school holidays) and all year round (e.g., winter and summer seasons). In some cases, parents' short-term focus was reinforced by reading popular books that advocate early specialization (e.g., Syed, 2010). One coach explained this situation: "For a new parent it is difficult because the messages conveyed by the talent ID process, the tournament schedule, ratings and rankings run contradictory to the research and evidence that suggests that this is a long-term exercise" (Coach 6).

As a result, participants felt that parents need to be educated about child and talent development to make informed decisions about their child's tennis development. As one parent explained: "Children are not just small adults, physiologically and psychologically, everything about them is different, I think that a real understanding of child development is needed" (Parent 1).

Specifically, participants believed that during mini tennis, parents need to be educated how to create an environment that fosters learning and intrinsic motivation to "make sure they [players] are willing to go back every week and want to get better and really enjoy the experience" (Ex-player 2). To 
achieve this, coaches felt parents need to understand how to manage their child's training schedule.

The following analogy illustrates this point:

Please don't over train your kids overtraining will only cause damage. My favorite meal is salmon, I love it, now if my wife gives me raw salmon every day for the next month I'll bet you anything I'm going to hate it, give me the right portions that keeps me enjoying it, keeps me wanting it more. If you believe what you are doing is slightly going to disrupt their love for it [tennis], ease off and wait until they are ready (Coach 7).

In addition to this, participants felt that parents need to understand that: "It [tennis] is lonely in comparison to other sports, so to keep your child engaged, you have to pick and choose your tournaments where you see people that he [or she] knows have entered. It's also important not to travel too far when they are little because they don't like spending time in the car" (Parent 13). Furthermore, coaches believed that entering appropriate level tournaments is vital for children's feelings of competence because "if your child doesn't win at least a reasonable proportion of the time they give up, so it's a very fine balance (Parent 13). Finally, coaches suggested that the best way to keep their child motivated during this stage is by participating in multiple sports and activities. The following example highlights this point:

Don't censor your child going out and having fun with his friends and playing football, just because he's going to have an extra hour of tennis [training], because what that hour of football is going to teach him, tennis is not. For example, with [child's name], I said 'forget about [tennis] lessons, play football!' and his father was saying 'how do I know that's going to help his tennis?' Well he is having fun, he is running, he is being kicked and he is being pushed, so it is helping his balance, his anger control, he is fighting and he is working hard; that's all you need in tennis. He is only six. When he is 14 and I tell you 'okay now your son is good enough to become a full-time player, now is the time to make the sacrifice', that is the time to put it all in. Don't put it all in when he is five so when he's seven he is worn out. The 
balance needs to be good (Coach 2).

Competition needs (f). Within the competition context, observations revealed that parents often have to fulfill multiple roles. As one parent explained: "At the tournaments, it's just me and him, so you have to be the coach and you have to be the parent" (Parent 6). Specifically, participants felt that parents need educating how to fulfill pre-match, in-match and post-match roles.

Pre-match roles. During informal chats, parents consistently admitted to not knowing what to say to their child prior to a match often causing them to unwittingly communicate in a manner that placed pressure on the child to win. Coaches felt that parents need education to understand that their pre-match role is to reinforce process goals that are related to the skills their child is learning in training. The following example from a coach describes this process:

We were practicing, and somehow he thinks that we want him to win really badly. So I talked to him and said 'all we want you to do is to do what you do in practice and play like you do in practice and forget about the winning, because the winning is pointless if you are doing it wrong'. So I had to sit him down and decide what sort of process he was going to follow in the match and what goals, so he stays in training mode and is able to perform (Coach 2).

Participants also felt that, given the prevalence of cheating in junior tennis, parents should be educated how to set behavioral expectations that reflect good morals (e.g., sportspersonship). One coach explained how important this is:

Parents need to teach players from a very young age that you have to be fair even if it hurts, you have to be honest, and you have to respect your opponent regardless of how good or bad he is. I believe that respect, integrity, being honest, being fair, and accepting the outcome has to be taught in the beginning (Coach 7).

As a final point, participants believed parents should also be educated how to take more of an active role in backing up and helping their child develop values (e.g., hard work, commitment, discipline), a positive attitude, and basic coping skills or strategies as these were believed to serve as 
11 foundations for the child's success later in their career. One parent explained this role: "You can't

2

3

4

63

7

84

9

10

$11^{5}$

12

136

14

15

change the world around you, what you have to do is help your son to build coping mechanisms to help your child through events" (Parent 1).

In-match roles. During matches, parents consistently mentioned the need for education to help them control the emotions of watching their child play. One parent explained how she feels when watching her son play tennis: "My stomach would be churning, I would feel sick, it's that fight or flight feeling, and it's innate those powerful emotions for your child" (Parent 1). Observations revealed that these emotions were often amplified if parents or their child placed a high value on the outcome of the match or tournament (e.g., ranking, rating points, selection) and their child was losing, performing badly or had been cheated. The following quote highlights the impact this can have on parents' behavior:

The worst example we had was when my youngest daughter played and this father was calling my daughter blind for not calling balls [out]. He was making lots of comments and he was swearing, and very shortly after he got in a physical fight and the police had to be called. His daughter was on court calling up and saying ‘daddy what are you doing?' In fact she doesn't play tennis anymore. It's so stressful and he couldn't control his emotions but I feel the signs quite often are there before. More proactive help could stop it (Parent 12).

Participants felt that parents would benefit from learning strategies to cope with their emotions whilst watching. One parent suggested that parents need to be taught "relaxation methods like breathing techniques to control their own emotions at a tournament, and give them techniques that they could try and they'll find their own one that works best for them" (Parent 3). Coaches and players also felt that tennis parents' in-match roles included ensuring that their body language was consistent with the goals set pre-match and that they role modeled appropriate values, morals, and attitudes. As one coach explained: "Acting how they want their child to act is so important. They [children] tend to pick things up and if they think things are acceptable then they'll try and do it as 
well. I think being a role model is massive for the parents" (Coach 10).

Post-match roles. During fieldwork, it became clear that after matches, parents were often the main source of feedback yet lacked confidence in their ability to provide it. Parents frequently said that they felt "embarrassed if things go wrong" (Parent 6) and "it turns into an argument and they start shouting, screaming and crying" (Parent 11). The following quote from a coach emphasizes this point: "I've had parents saying to me 'I don't know what to say' after the child has lost a match, hasn’t played well or has behaved badly on court" (Coach 9). Participants felt that in order to fulfill this post-match role, parents need to understand how to communicate after a match and when to provide feedback. Specifically, coaches highlighted the need to educate parents to let the child speak first, ask open questions, and facilitate reflection in order to encourage players to learn, improve, and problem solve in the future. The following quote illustrates these points:

This [providing feedback] is no different to coaching, because I guess in that capacity you are coaching as a parent. Little things like letting them speak first, it's a golden rule I have for myself. When I speak to players after matches, no matter how wound up I might be, like 'this kid is getting such a rollicking when they come off the court!', I've got my whole script ready to go, I force myself always to say 'how was it out there, how did it go for you?' and that invariably takes things in very different directions. Just little tricks of the trade that we might pick up as coaches which parents could really benefit from (Coach 6).

Coaches also felt that parents need educating to ensure that their own feedback is positive and reflects the process goals and behavioral expectations, which were set pre-match, rather than the outcome. One coach concluded:

There is one magical thing that they [parents] can do and that is helping their youngster grow from the things that they see happening positively on the court. The job of parents is to 'catch the kids being good', even if that good is in a sea of mediocrity. Build on that, get attracted by that, not by the millions of other things they can't do (Coach 5). 


\section{An Educational Sub-Process for Tennis Parents during Early Adolescence/Junior Tennis}

As players transitioned from childhood/mini tennis to early adolescence/junior tennis, parents also experienced a transition and required additional education at an organizational and developmental level (see Figure 2). Therefore, an additional educational sub-process consisted of the following sub-categories: Early adolescence/junior tennis organizational needs and early adolescence/junior tennis development needs.

Early adolescence/Junior tennis organizational needs. At an organizational level, participants identified the need to educate parents to understand the transition period from mini tennis to junior tennis and the differences in the LTA's system at this stage. As one parent explained: “I don't think there's enough on the transition period for parents, I could really do with some parent education from mini tennis into yellow [full] ball" (Parent 5). Parents consistently referred to the differences in the rating, ranking, and funding systems during this stage as sources of stress. As a result, participants felt that education is needed to ensure parents know what grade tournaments to enter depending on the level of their child, how rankings and ratings work, and how funding is distributed during these stages. The following quote captures these points:

The parents understand the mini tennis system, but they don't know the rating systems for the 10 's and above. We've recently gone through that with a couple of parents on an individual basis so they understand how that new system works in terms of ranking points, how to get into events, and what happens if they can't get into the level of events they need to. It's a different world again (Coach 9).

Beyond the British system, some children competing at a national level often started to compete against international opposition during this stage. Consequently, participants felt that educating parents about Tennis Europe and International Tennis Federation (ITF) tournaments and how to enter them was important. One parent of a national player explained: "There is not enough information for parents to understand the route to get from mini tennis through to senior tennis, I 
11 don't really know anything about 'Tennis Europe' [competitions]. They need to start showing where

2

you can branch off into 'Tennis Europe' and then how you can get to 'ITF' [competitions]' (Parent 10).

Early adolescence/Junior tennis development needs. Informal chats and observations revealed how the transition from mini tennis to full ball tennis was accompanied by a gradual increase in pressure to achieve results. As one coach explained: "As they get older the competitive pressure gets greater because the results are needed, you have to get results as you start getting into U14's otherwise you fall by the wayside" (Coach 1). Observations also revealed how biological changes during this transition can make achieving results more difficult for players who develop later. The following quote from a father supports this point: "it's a big, big, big step up, the girls are a lot bigger, stronger and are making a lot more balls so we found that a challenge. You can get a bit lost and start to lose interest" (Parent 10). Consequently, the pressure of "trying to keep at the top of the tree" (Parent 8) combined with the realization that "a lot of kids that are moving towards the top are full-time and doing a lot more hours than you are" (Parent 10) caused some parents to make the decision to take their child out of school for lessons, increase the number of evening training sessions, or in some cases leave school and train full time in the academy from the age of 11 . The following quote captures the current situation:

There is always this looking over your shoulder trying to make sure that someone else isn't doing more than you are. Most parents are not experts in the game of tennis, and therefore, their default will be to fall back to more is better. That perception isn't helped by what are sometimes myths of tennis on the continent that they just play more and spend six hours a day on court. At an international U14 to U16 level, volume undoubtedly plays a big part but at U12 and U14 you have to be very conscious of the long-term aspect of making sure that players are not burning themselves out, getting injured, or falling out of love with the game. I've had instances of that even this year where, by jumping through hoops and getting caught 
up in feeling like you need to be in the top three in the country at a young age, behind the scenes that the poor little girl involved was gradually losing her passion and love for the game unnoticed by anybody. Then, suddenly she turns around at 12 years old and says 'do you know what, I don't want to do this anymore' (Coach 6).

Coaches felt that parents need to understand their child's goals at this stage and what they were looking to achieve long-term in tennis. As one ex-player explained: "I don't think enough parents sit down with their kids like once a month, or once a term to identify goals... and then sit down with the coach and say this is what we want to do...more goal setting and seeing where they want to go during the middle stage" (Ex-player 1). Coaches felt that parents then need to be educated about the pathways that are available to their child and the impact that following each pathway may have on their child's tennis, education, and social life. As one coach explained: “At U14's it is helping parents understand where do we go from here, what are the different routes, what are the different pathways" (Coach 6).

For early adolescents with ambitions of pursuing tennis at a national or international level, there was a general consensus that players had to start specializing by training and competing in tennis more during this stage. However, participants felt that parents need to be made aware that increased tennis involvement at this stage can potentially have a negative impact on early adolescents education and social development. As one dad explained: "whilst she was at school, tennis impacted on it [education] greatly, because she would go off to talent ID days, 3-day camps, tournaments that would actually go into the school week, national camp days, training days and she would be out a day and a half, every week. It did impact on her core subjects, like reading and math, they are the ones you notice" (Parent 10). Another mum admitted the impact this can have socially: "[Child's name] doesn't have that many friends because all his other normal friends at school do after school clubs or stuff like that, or see each other at weekends. But obviously our weekends are taken up by tournaments, or he has rest...He does find it hard to mix with other children in bigger groups" 
(Parent 6). These educational and social issues were often magnified if children trained full-time and were educated in high performance centers. The following quote highlights the need to make parents aware of the impact that following this pathway can have on early adolescents' metal health:

Before I came into tennis I wasn't aware of depression but three of the [full-time] players at the academy are suffering from aspects of frustration, anger and are a bit depressed sometimes. It's tough to be friends with people you are competing against. Tennis is so life consuming; you don't have time outside of it to get the tennis/social life balance so you struggle to develop social skills. It's a brutal world for the top national and international juniors, what they have to go through, it's not a stable existence" (Coach 3).

Participants felt that understanding the potential impact of following these pathways was important to ensure that parents were able to make informed decisions, with their child, about the best pathway to follow during early adolescence. The following quote captures the importance of involving players in this decision: "Once the kid is past ten, past the mini tennis stage, you are trying to encourage them to be more independent, but you need to nurture them through the decisionmaking process because life is about making good decisions on court and off court, so I think that's the bit that evolves" (Coach 8). As a final point, participants felt that parents also need to continually monitor their child's goals and the pathway they are on. One mother explained the reasons for this during an informal chat: "the goalposts move all the time depending on how old they are and where they are within their game of tennis. You have to keep reviewing it the whole time, constant reviews. It's not rigidly concrete, it's never static either".

\section{A Grounded Theory of Tennis Parents' Education and Support Needs}

This substantive theory offers an explanation of the education and support needs of British tennis parents across contexts and developmental stages. In doing so, the theory can be used as the basis for a structured and proactive approach to tennis parent education and support, which addresses parents' needs at a social, organizational, developmental and intra-interpersonal level. The grounded 
11 theory is based on the notion that tennis parents require additional information as they go through

2

${ }_{4}^{3} 2$

5

63

7

84

9

10

$11^{5}$

12

136

14

15

each transition, which adds to their existing knowledge base rather than replaces it. Despite this

structured approach, the model allows flexibility within individual cases (based on parents existing knowledge and experience) and should not be seen as a rigid educational process, rather as a tool to guide education at each stage. The bi-directional arrow also allows an educator to tailor the education they provide to parents based on their child's development age (e.g., level of maturation) and/or their level of involvement in tennis.

The theory is based on the notion that parents education and support needs can only be

fulfilled when parents are willing to learn and enter into a supportive learning environment which provides them with formal education and on-going support (i.e., regular meetings) (a). Tennis parents' first educational needs (i.e., introductory needs) refer to understanding how social factors (e.g., financial and time demands, reasons for involvement, knowledge of tennis) underpin their participation and type of involvement in junior performance tennis (b). Once involved, the theory suggests that parents then enter into an educational sub-process based on their child's age within the British tennis system (c). Within each educational sub-process, education is needed to address tennis parents' organizational needs (d). At this point, the theory demonstrates the relationship between organizational and development-based needs, with the short-term nature of the British tennis system influencing the need to educate parents about child and talent development. This understanding is essential for parents to make informed decisions about their child's tennis involvement and create an environment that facilitates participation and development at each stage (e). The theory suggests that this understanding also acts as the foundation for parents' to understand and fulfill their roles within the competition context (f).

\section{Discussion}

The purpose of the study was to develop a grounded theory of tennis parents' education and support needs across contexts and developmental stages within British high performance centers. 
11 When comparing the grounded theory to existing tennis parent research and theories, many of the

2

3

4

5

63

7

84

10

$11^{5}$

12

136 14

15

education and support needs identified encouragingly reinforce current recommendations and guidelines for working with sport parents within the literature (see Holt \& Knight, 2014). For instance, the need to educate parents about who or where they can turn to for support, how this support can be helpful, and ways to develop and maintain relationships with significant others, have been well documented in the youth sport literature (Knight \& Holt, 2013a, 2013b; Smoll, Cumming \& Smith, 2011). Findings also support research which has suggested that sport parents need to understand how their own reasons for involvement (i.e., the goals they have for their child) (Knight \& Holt, 2014), their financial and time commitments (Harwood \& Knight 2009a; 2009b), and their understanding of tennis (Knight \& Holt, 2014) can influence their type of involvement (i.e., unsupportive, supportive, pressurizing). In addition to this, the need to work with parents to help them manage the organizational, developmental, and competitive stressors they experience has been widely recommended (Harwood \& Knight, 2015). Finally, the tennis parent literature has consistently highlighted the need to educate parents in relation to appropriate and inappropriate behaviors and how to communicate effectively with their child in the competitive environment (Gould et al., 2006, 2008; Lauer et al., 2010a, 2010b). However, the current study also offers a number of contributions that extend and advance the tennis parent literature, particularly in relation to applied practice.

The proposed theory moves beyond a decontextualized view of parent education by illustrating the range of contextual factors that influence parents' education and support needs. Although tennis parent research has provided an understanding of how the tournament context influences parents' experiences (e.g., Knight \& Holt, 2013a), the current study illustrates how parents’ involvement is also influenced by overarching social characteristics (e.g., financial and time demands), indirect organizational factors (e.g., LTA's rating system), and the high performance center setting. Although the current study was not guided by Brofenbrenner's (2005) ecological 
systems theory, findings here support the notion that in order to understand and enhance development, the entire environment in which development occurs must be considered. Furthermore, by revealing the interactions between parents and their environment, the grounded theory highlights the need to create structured educational programs that address tennis parents' needs across multiple levels of functioning (i.e., social, organizational, developmental, and intra/interpersonal levels). However, it is important to note that education at a development level is likely to prove problematic for practitioners given that there appears to be substantial differences of perception between the research data and the current Lawn Tennis Associations practice in talent development (see Pankhurst, Collins, \& MacNamara, 2012). There is clearly a need for policy level changes to reduce some of the social (i.e., the cost of participation) and organizational factors (i.e., emphasis on results from an early age) which are negatively influencing tennis parents' (and players') experience and involvement but are difficult to address through education alone.

The grounded theory also extends previous research (e.g., Knight \& Holt, 2013a, 2013b) by highlighting how parents' education and support needs are influenced by the developmental stage that they operate within. Specifically, the current study demonstrates how parents' needs change alongside their roles, experiences, and demands as their child progresses through tennis (Côté, 1999; Harwood \& Knight, 2009b; Lauer et al., 2010a, 2010b). Importantly, the specific timing of these changes was determined by organizational and development-level transitions that were specific to the British tennis system. Understanding the needs of parents within each developmental stage and the timing of key transitions will enable practitioners (e.g., coaches, sport psychologists) to provide British tennis parents with education in advance of each transition, rather than learning as they go through the experience (Knight \& Holt, 2013b). Proactive education will not only help parents to successfully navigate each transition, but also create a more developmentally appropriate youth sport environment at each stage. These findings also emphasize the need to move beyond the use of generic models or stages of talent development (Bloom, 1985; Côté, 1999) to guide development- 
orientated research within the youth sport domain (e.g., Harwood \& Knight, 2009b).

Results here also extend the tennis parent literature by providing an understanding of how parent education and support needs can be fulfilled. Traditionally, researchers have focused on producing broad one-size-fits-all guidelines and recommendations for sport parent education (see Holt \& Knight, 2014). In contrast, the current study highlights the specific knowledge and skills (i.e., organizational, decision-making, interpersonal and intrapersonal) tennis parents need to prevent, manage, or cope with the unique demands they experience in British tennis (Harwood \& Knight, 2015). Such insights are essential for the development of educational materials that are tailored to meet the needs of tennis parents operating within the British tennis system. Doing so aligns with theories from the field of adult education, which suggest that the closer education is linked to the actual practice setting and the needs of the participants (rather than decontextualized topics), the more likely that parents will be motivated to learn and that learning will lead to a change in practice (Knowles, Holton, \& Swanson, 1998; Merriam \& Leahy, 2005).

Expanding this point, the current theory highlights how this learning process can be optimized or facilitated. In line with existing research (e.g., Dorsch et al., 2009; Knight \& Holt, 2013b), the majority of tennis parents in the current study also appeared to learn through a combination of informal and self-directed learning. However, the theory suggests that these forms of practical learning can be facilitated when guided by more formalized educational provision (e.g., one-to-one tutoring, group-based workshops). This is consistent with the notion that education can 'scaffold' real world activities and problems, enabling learners to develop new forms of expertise (Vygotsky, 1978). The proposed theory also suggests that the effectiveness of this education is likely to be dependent upon individual parents' willingness to learn and the on-going support they receive from key stakeholders (e.g., coaches, other parents). These findings align with studies that have shown one-toone mentoring, feedback, and support from peers can reinforce key messages and facilitate learning transfer in adult education (Merriam \& Leahy, 2005). As a final point, an interesting finding to 
emerge from the current study was how psychologists worked directly with a small number of parents and families to help them cope with and overcome individual challenges they were facing (e.g., children's mental health problems or developmental disorders). This highlights the need to not only integrate educational provision that meet the needs of British tennis parents as a group, but also to ensure that coaches and psychologists are available in a consultancy capacity to support parents with specific needs (see Holt \& Knight, 2014 for a review of family system approaches).

Overall, the grounded theory provides an understanding of the wide range of factors that influence British tennis parents' current experiences and involvement. By identifying the gap between parents' current and desired experiences and involvement, the current study was able to determine what tennis parents' education and support needs are and how they can be fulfilled. Interestingly, these desired behavioral outcomes largely align with Harwood and Knight's (2015) postulates of expertise in sports parenting. Therefore, based on the proposed theory, it likely that only through understanding and fulfilling parents' education and support needs within specific youth sport settings are practitioners going to assist in developing parents' levels of expertise.

The use of the proposed grounded theory should be considered against the limitations of this study. First, the current investigation did not explore the education and support needs of parents with players in mid-to-late adolescence. Identifying the needs of tennis parents during this stage when they are less visibly involved represents a logical avenue for future research. In addition, data were collected in two high performance centers, and therefore reflects the education and support needs of parents whose children are regularly training and competing at a county, regional, and national level. Consequently, these needs may not be representative of parents' needs in lower level performance centers or local clubs. Therefore, applied researchers are encouraged to explore tennis parents' education and support needs within these social settings. It would also be informative to consider how the education and support needs identified in this study compare and contrast with parents' needs in other cultures, organizational systems, or even sports (e.g., soccer). 
In conclusion, the current study answers calls to provide a better understanding of how to structure and deliver parent education programs and how to intervene with sport parents (Holt \& Knight, 2014). This paper offers a framework that has practical use for coaches, psychologists, high performance tennis centers, and the governing body, and therefore achieves the desired outcome of a grounded theory research design (Corbin \& Strauss, 2008). It is, therefore, timely to reaffirm the need for interventions that address tennis parents' education and support needs. The lack of intervention studies, or even applied initiatives, within junior performance tennis is surprising given the depth of research which has explored parental involvement (Harwood \& Knight, 2012). Despite almost a decade of research, tennis parents in Britain still receive little or no education about how to facilitate their child's tennis participation and development. It is hoped that the current study can bridge the gap between theory and practice and facilitate the development of a parent education program for British tennis parents. 


\section{References}

Bloom, B. (1985). Developing talent in young people. New York: Ballantine Books.

Bronfenbrenner, U. (2005). Making human beings human: Bioecological perspectives on human development. Thousand Oaks, CA: Sage.

Clarke, N.J., \& Harwood, C.G. (2014). Parenting experiences in elite youth football: A phenomenological study. Psychology of Sport and Exercise, 15, 528-537. doi.org/10.1016/j.psychsport.2014.05.004

Corbin, J. C., \& Strauss, A. (2008). Basics of qualitative research (3rd ed.). Thousand Oaks, CA: Sage.

Côté, J. (1999). The influence of the family in the development of talent in sport. The Sport Psychologist, 13, 395- 417.

Dewey, J. (1922). Human nature in conduct. New York, NY: Henry Holt.

Dorsch, T. E., Smith, A. L., \& McDonough, M. H. (2009). Parents' perceptions of child-to-parent socialization in organized youth sport. Journal of Sport \& Exercise Psychology, 31, 444-468.

Gould, D., Lauer, L., Rolo, C., Jannes, C., \& Pennisi, N. (2006). Understanding the role parents play in tennis success: A national survey of junior tennis coaches. British Journal of Sports Medicine, 40, 632-636. doi:10.1136/bjsm.2005.024927

Gould, D., Lauer, L., Rolo, C., Jannes, C., \& Pennisi, N. (2008). The role of parents in tennis success: Focus group interviews with junior coaches. The Sport Psychologist, 22, 18-37.

Harwood, C.G., \& Knight, C.J. (2009a). Understanding parental stressors: An investigation of British tennis-parents. Journal of Sports Sciences, 27, 339-351. doi:10.1080/02640410802603871.

Harwood, C.G., \& Knight, C.J. (2009b). Stress in youth sport: A developmental investigation of tennis parents. Psychology of Sport and Exercise, 10, 447-456. doi:10.1016/j.psychsport.2009.01.005 
Harwood, C.G., \& Knight, C.J. (2012). The role of parents in the development of tennis players: The past, the present and the future. Journal of Medicine and Science in Tennis, 17(1), 9-15.

Harwood, C.G., \& Knight, C. J., (2015). Parenting in youth sport: A position paper on parenting expertise. Psychology of Sport and Exercise, 16, 24-35. doi:10.1016/j.psychsport.2014.03.001

Holt, N.L. \& Knight. C.J. (2014). Parenting in youth sport: from research to practice. London: Routledge.

Holt, N. L., \& Tamminen, K. A. (2010). Moving forward with grounded theory in sport and exercise psychology. Psychology of Sport and Exercise, 11, 419-422. doi:10.1016/j.psychsport.2010.07.009.

Holt, N. L., Tamminen, K. A., Black, D. E., Mandigo, J. L., \& Fox, K. R. (2009). Youth sport parenting styles and practices. Journal of Sport \& Exercise Psychology, 31, 37-59.

Holt, N. L., Tamminen, K. A., Black, D. E., Sehn, Z. L., \& Wall, M. P. (2008). Parental involvement in competitive youth sport settings. Psychology of Sport and Exercise, 9, 663-685. doi:10.1016/j.psychsport.2007.08.001.

Horn, T. S., \& Horn, J. L. (2007). Family influences on children's sport and physical activity participation, behavior, and psychosocial responses. In G. Tenenbaum \& R. C. Eklund (Eds.), Handbook of sport psychology (3rd ed.). (pp. 685-711) New York: Wiley.

Knight, C. J., Boden, C. M., \& Holt, N. L. (2010). Junior tennis players' preferences for parental behaviors. Journal of Applied Sport Psychology, 22, 377-391. doi:10.1080/10413200.2010.495324.

Knight, C. J., \& Holt, N. L. (2013a). Parents' experiences at junior tennis tournaments in Western Australia. Sport, Exercise, and Performance Psychology, 2, 173-189. doi:10.1037/a0031203

Knight, C. J., \& Holt, N. L. (2013b). Strategies used and assistance required to facilitate children's involvement in competitive tennis: Parents' perspectives. The Sport Psychologist, 27, 281291. 
Knight, C.J., \& Holt, N.L. (2014). Parenting in youth tennis: understanding and enhancing children's experiences. Psychology of Sport and Exercise, 15, 155-164.

Knight, C. J., Neely, K. C., \& Holt, N. L. (2011). Parental behaviors in team sports: How do female athletes want parents to behave? Journal of Applied Sport Psychology, 23, 76-92. doi:10.1080 $/ 10413200.2010 .525589$

Knowles, M., Holton, E.F., \& Swanson, R.A. (1998). The adult learner: The definitive classic in adult education and human resource development ( $5^{\text {th }}$ Ed.). Houston, TX: Gulf Publishing Company.

Lauer, L., Gould, D., Roman, N., \& Pierce, M. (2010a). Parental behaviors that affect junior tennis player development. Psychology of Sport and Exercise, 11, 487-496. doi:10.1016/j.psychsport.2010.06.008.

Lauer, L., Gould, D., Roman, N., \& Pierce, M. (2010b). How parents influence junior tennis players' development: Qualitative narratives. Journal of Clinical Sport Psychology, 4, 69-92.

Mahoney, G., Kaiser, A., Girolametto, L., MacDonald, J., Robinson, C., Safford, P., \& Spiker, D. (1999). Parent education in early intervention: A call for a renewed focus. Topics in Early Childhood Special Education, 19, 131-140. doi:10.1177/027112149901900301

Merriam, S.B., \& Leahy, B. (2005). Learning transfer: A review of the research in adult education and training. Journal of Lifelong Learning, 14, 1-24.

Omil, J., \& LaVoi, N. M. (2012). Emotional experiences of youth sport parents I: Anger. Journal of Applied Sport Psychology, 24, 10-25. doi:10.1080/10413200.2011.578102

Pankhurst, A., Collins, D., \& Macnamara, A. (2013). Talent development: linking the stakeholders to the process, Journal of Sports Sciences, 31 (4), 370-380. doi:10.1080/02640414.2012.733821

Smoll, F. L., Cumming, S. P., \& Smith, R. E. (2011). Enhancing coach-parent relationships in youth sports: increasing harmony and minimizing hassle. International Journal of Sports Science and Coaching, 6, 13-26. http://dx.doi.org/ 10.1260/1747-9541.6.1.13. 
Sparkes, A.C., \& Smith, B. (2014). Qualitative research in sport, exercise \& health sciences. From process to product. London: Routledge

Syed, M. (2010). Bounce. London: Fourth Estate.

Tamminen, K.A., \& Holt, N.L. (2012). Adolescent athletes' learning about coping and the roles of parents and coaches. Psychology of Sport \& Exercise, 13, 69-79. doi:10.1016/j.psychsport.2011.07.006

Tracey, S.J. (2010). Qualitative quality: Eight "Big-Tent" criteria for excellent qualitative research. Qualitative Inquiry, 16, 837-851. doi:10.1177/1077800410383121

Vygotsky, L. S. (1978). Mind in society. Cambridge, MA: Harvard University Press.

Weed, M. E. (2009). Research quality considerations for grounded theory research in sport \& exercise psychology. Psychology of Sport and Exercise, 10, 502-510. doi:10.1016/j.psychsport.2009.02.007.

Wiersma, L. D., \& Fifer, A. M. (2008). “The schedule has been tough but we think it's worth it”: The joys, challenges, and recommendations of youth sport parents. Journal of Leisure Research, $40,505-530$.

Wylleman, P., \& Lavallee, D. (2004). A developmental perspective on transitions faced by athletes. In: M. Weiss (Ed.), Developmental sport and exercise psychology: A lifespan perspective (pp. 507-527). Morgantown, WV: Fitness Information Technology. 
1

2

3

4

5

6

7

8

9

10

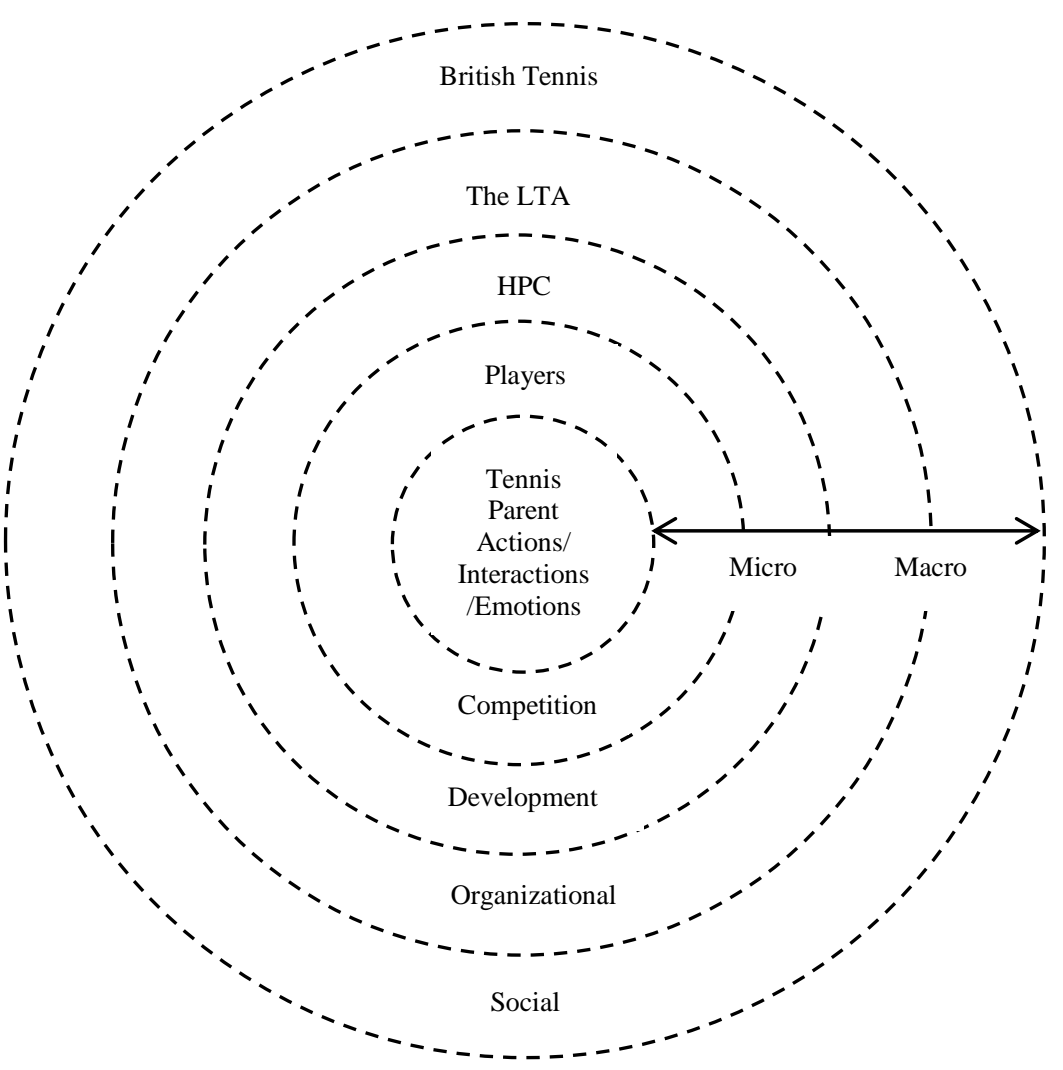

Figure 1. Conditional/consequential matrix of tennis parents' education and support needs Note. LTA=Lawn Tennis Association; HPC=High Performance Center 


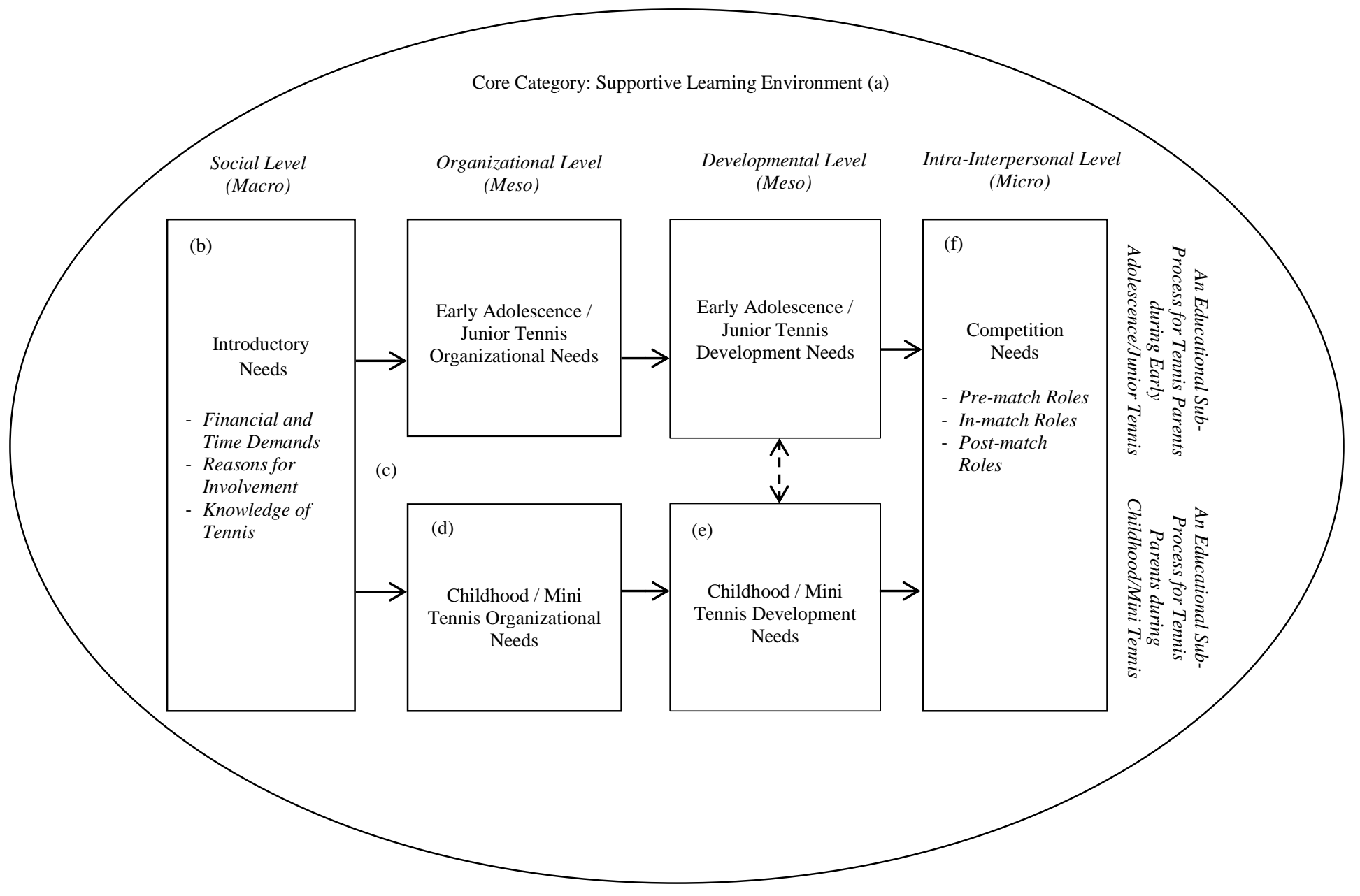

Figure 2. A grounded theory of tennis parents' education and support needs during childhood/mini tennis and early adolescence/junior tennis 
1 Table 1

2 Participant Demographics

\begin{tabular}{|c|c|c|c|c|c|c|c|c|c|c|c|c|c|c|}
\hline \multirow[t]{2}{*}{ Population } & \multirow[b]{2}{*}{$\mathrm{n}$} & \multicolumn{3}{|c|}{ Player Age (Years) } & \multicolumn{2}{|c|}{ Gender } & \multicolumn{5}{|c|}{ Player Standard } & \multicolumn{3}{|c|}{ Years of Experience } \\
\hline & & $M$ & $S D$ & Range & Male & Female & Club & County & Regional & National & International & $M$ & $S D$ & Range \\
\hline \multicolumn{15}{|l|}{ Mini Tennis Parents } \\
\hline (Parents 1-5) & 5 & 9.4 & 0.89 & $8-10$ & 1 & 5 & 2 & 0 & 1 & 2 & 0 & 3.8 & 2.17 & $1-6$ \\
\hline \multicolumn{15}{|l|}{ Junior Tennis Parents } \\
\hline (Parents 6-13) & 8 & 12.5 & 1.31 & $11-14$ & 3 & 5 & 0 & 0 & 2 & 5 & 1 & 10.63 & 4.66 & $6-20$ \\
\hline Coaches & 12 & & All Age & & 10 & 2 & & & All Standa & & & 18.33 & 11.23 & $5-37$ \\
\hline Ex-Youth Players & 4 & 20.5 & 0.58 & $20-21$ & 2 & 2 & 0 & 0 & 0 & 2 & 2 & 13.5 & 1.91 & $12-16$ \\
\hline
\end{tabular}

3 

Supplemental Material - Additional
Click here to download Supplemental Material - Additional: Response To Reviewers Comments .docx

Supplemental Material - Additional
Click here to download Supplemental Material - Additional: Response To Reviewers Comments .docx

$x$

